\title{
Assistência à pessoa com hipertensão arterial na ótica do profissional de saúde
}

Assistance for people with hypertension in the perspective of the health professional

Asistencia para personas con hipertensión en la perspectiva del profesional de salud

\section{Maria Angélica Pagliarini Waidman', Cremilde Aparecida Trindade Radovanovic", Michelle Caroline Estevam"I', Sonia Silva Marcon' ${ }^{\text {IV }}$}

' Universidade Estadual de Maringá, Centro de Ciências da Saúde, Departamento de Enfermagem, Programa de Pós-graduação em Enfermagem. Maringá-PR, Brasil.

"Universidade Estadual de Maringá, Centro de Ciências da Saúde, Departamento de Enfermagem, Programa de Pós-graduação em Ciências da Saúde (Doutoranda). Maringá-PR, Brasil.

II' Secretaria Municipal de Saúde, Serviço de Pronto Atendimento. Marialva-PR, Brasil.

"N Universidade Estadual de Maringá, Centro de Ciências da Saúde, Departamento de Enfermagem, Programa de Pós-graduação em Enfermagem. Maringá-PR, Brasil.

\author{
Submissão: 22-10-2010 Aprovação: 19-07-2012
}

\section{RESUMO}

Objetivou-se conhecer a assistência prestada às pessoas com hipertensão arterial na Atenção Básica sob a ótica dos trabalhadores da saúde. A coleta de dados ocorreu por meio de grupos focais, em cinco municípios do Noroeste do estado do Paraná. Observou-se que, apesar de o estudo ter sido realizado com equipes de diferentes municípios, os significados e percepções relativos ao atendimento prestado e às dificuldades experenciadas são semelhantes em muitos aspectos. De modo geral, as Unidades Básicas de Saúde atendem às necessidades mais urgentes dos usuários, apesar de a adoção de estratégias para adesão ao tratamento, por vários motivos, não conseguirem atingir toda a população, o que prejudica a qualidade da assistência, mesmo havendo empenho da equipe.

Descritores: Doença Crônica; Hipertensão; Família; Atenção Primária a Saúde.

\section{ABSTRACT}

The study aimed at learning about the care provided to people with hypertension in primary care from the perspective of health workers. The data was collected through focus groups in five cities in the northwest of the state of Paraná. It was observed that, although the study was conducted with teams of different municipalities, the meanings and perceptions regarding the care provided and the difficulties experienced are similar in many aspects. In general, the Basic Health Units meet the most urgent needs of users, despite the adoption of strategies for treatment adherence, for various reasons, cannot reach the entire population, undermining the quality of care, even with the commitment of the team.

Key words: Chronic Disease; Hypertension; Family; Primary Health Care.

\section{RESUMEN}

El objetivo del estudio fue conocer la asistencia prestada a las personas con hipertensión arterial en la Atención Básica en Salud bajo la óptica de los trabajadores. La recogida de datos ocurrió por medio de grupos focales, en cinco municipios en el noroeste del Estado de Paraná. Se observó que a pesar del estudio haber sido realizado con equipos de diferentes municipios, los significados y percepciones con relación a la atención prestada y las dificultades experimentadas son semejantes en muchos aspectos. De una manera general, las Unidades Básicas de la Salud estudiadas atienden las necesidades más urgentes de los usuarios. A pesar de la adopción de estrategias para adhesión al tratamiento, no consiguen alcanzar toda la población por varios factores, implicando en la calidad de la asistencia, mismo habiendo comprometimiento del equipo.

Palabras clave: Enfermedad crónica; Hipertensión; Familia; Atención Primaria de Salud. 


\section{INTRODUÇÃO}

A principal causa de morbimortalidade na população brasileira são as doenças cardiovasculares, sendo a hipertensão arterial (HA) um dos principais fatores de risco para o agravamento desse cenário, por estar relacionada ao surgimento de outras doenças crônicas não transmissíveis que repercutem negativamente na qualidade de vida ${ }^{(1)}$. As sequelas atribuídas à falta de controle adequado dos níveis pressóricos incluem, além dos agravos cardiovasculares e renais, a ocorrência de morte prematura, em uma fase na qual o indivíduo é economicamente ativo, representando grande ônus social e econômico ${ }^{(2)}$.

Os dados do Ministério da Saúde ${ }^{(3)}$ descrevem a magnitude deste problema, demonstrando preocupação com os aspectos humanos e econômicos. As doenças cardiovasculares (DCV), por exemplo, são responsáveis por $31,88 \%$ das causas de óbito no Brasil.

A HA implica em transformações expressivas na vida dos indivíduos em várias esferas, como a psicológica, a familiar, a social e a econômica, pela possibilidade de agravo em longo prazo, o que resulta, geralmente, em mudanças nos hábitos de vida, exigindo esforços não apenas dos portadores, mas também de seus familiares, das pessoas próximas e dos profissionais de saúde.

O aumento do número de indivíduos com doenças crônicas reforça a necessidade de um modelo de atenção à saúde que permita ao profissional conhecer a realidade onde ele atua e, consequentemente, traçar estratégias de intervenção que tenham êxito e possam ser aplicadas a um maior número de pessoas.

Em meio às diferentes possibilidades que vêm sendo experimentadas no âmbito da reorganização dos serviços de atenção à saúde, o Programa Saúde da Família (PSF), concebido pelo Ministério da Saúde (MS) em 1994, e hoje denominado Estratégia Saúde da Família (ESF), propõe a promoção da qualidade de vida e intervenção nos fatores que a colocam em risco, permitindo a identificação mais acurada e um melhor acompanhamento dos indivíduos. Por esse e outros motivos o PSF vem se consolidando como eixo reestruturante da Atenção Básica ${ }^{(4-5)}$.

Diante do exposto, o objetivo deste estudo foi conhecer os aspectos da assistência prestada às pessoas com HA na Atenção Básica em Saúde sob a ótica de profissionais que participaram desta assistência.

\section{MÉTODO}

Este estudo, de abordagem qualitativa, é parte do projeto de pesquisa intitulado "Avaliação da atenção à HA na Macrorregião Noroeste do Paraná: doenças cerebrovasculares como evento sentinela", realizado no âmbito de uma das cinco macrorregionais de Saúde do Estado do Paraná, a qual engloba 115 municípios, organizados em cinco regionais de saúde. O objeto do estudo foram os óbitos por doenças cerebrovasculares em indivíduos com idade entre 45 e 64 anos, ou seja, óbitos que não deveriam ter ocorrido nesta faixa etária, que poderiam ter sido evitados e que, por isto mesmo, são considerados como um evento sentinela.
Os dados foram coletados com o uso da técnica de grupo focal, nos meses de janeiro e fevereiro de 2008, em cinco municípios sedes de RS, mais especificamente nas equipes da ESF em cuja área de abrangência houve óbito por DCV de pessoas da faixa etária de 45 a 64 anos. O grupo focal é uma forma metodológica de coletar dados diretamente das falas de um grupo, que relata suas experiências e percepções em torno de um tema de interesse coletivo ${ }^{6}$. Tem como característica promover interações do pesquisador com pequenos grupos, favorecendo assim a reflexão sobre o tema pesquisado ${ }^{(7)}$. Ele permite aos participantes revelar suas experiências, sentimentos, necessidades, percepções, atitudes e preferências, e proporciona ao pesquisador captar em pouco tempo diferentes versões sobre um tema, assim como entender em profundidade o pensamento e os comportamentos do grupo pesquisado, permitindo observar os pontos consensuais e divergentes do grupo sobre o tema ${ }^{(7)}$.

Com o uso desta técnica, os dados são produzidos a partir da discussão focada em tópicos específicos e diretivos. A sessão não deve durar mais que uma hora e 50 minutos e o número de participantes deve variar de 5 a 15 pessoas, de modo que todos possam expressar sua opinião. Em sua condução, são necessárias três pessoas: o coordenador/moderador e dois observadores. O primeiro tem o papel fundamental de garantir, por meio de uma intervenção ao mesmo tempo discreta e firme, que o grupo aborde os tópicos de interesse do estudo da maneira menos diretiva possível. Um dos observadores anota os acontecimentos de maior interesse para a pesquisa (relator) e o outro auxilia na observação da comunicação não verbal, como forma de compreender os sentimentos dos participantes sobre os tópicos discutidos e, eventualmente, intervir na condução do grupo ${ }^{(6)}$.

$\mathrm{Na}$ realização do grupo focal utilizou-se um tópico-guia com a seguinte questão principal: "Como é o atendimento, nesta unidade, às pessoas com HÁ, que se encontram na faixa etária de 45 a 65 anos?". As questões secundárias foram: "Existe protocolo de atendimento à pessoa com hipertensão na unidade? Fale sobre seu uso". "Como é a rotina de atendimento à pessoa com hipertensão arterial? Fale sobre as facilidades e dificuldades que o serviço tem na assistência a estas pessoas". Ao final era lançada a seguinte questão: "Na área de abrangência desta unidade faleceu, no ano de 2006, uma pessoa com idade entre 45 a 64 anos tendo como causa básica a HÁ? O sr/sra (...). Vocês se lembram dela? Como era o seu acompanhamento no serviço?".

Os grupos foram realizados em horário indicado pela coordenação das unidades, de forma que deles pudesse participar um número de profissionais maior e constituído de diferentes categorias, a saber, enfermeiro, médico, dentista, auxiliar de enfermagem, técnico de enfermagem e agente comunitário de saúde e os três membros da equipe de pesquisa.

No início de cada sessão eram expostos o objetivo do encontro e o tema a ser debatido a partir do tópico-guia. Um único coordenador/facilitador experiente conduziu as atividades de todos os grupos, mas os observadores vários. O número de participantes em cada grupo variou de seis a 16. Nas sessões em que se contou com número maior de participantes, quando 
havia dispersão do grupo e fuga do tema proposto, o coordenador fazia um resumo dos temas discutidos com o intuito de retomar as discussões sobre o foco de interesse da pesquisa.

As discussões foram gravadas e registradas em diário de campo e posteriormente os dados foram transcritos e analisados seguindo-se a análise de conteúdo temática de Bardin ${ }^{(8)}$. Essa técnica de análise de dados constitui-se no conjunto de instrumentos metodológicos, em constante aperfeiçoamento, que se aplica às comunicações. É uma forma empírica dependente do tipo de comunicação e do objetivo que se queira alcançar ao analisá-lo. A análise de conteúdo trabalha as palavras e suas significações, ou seja, é uma busca de outras realidades através da mensagem em que se usa um mecanismo de dedução com base nos indicadores construídos a partir de uma amostra de mensagens particulares. Depois de analisados, os dados foram agrupados em duas categorias: $\mathrm{O}$ atendimento à pessoa com $\mathrm{HA}$ - características e dificuldades; e Estratégias de intervenção para adesão ao tratamento da hipertensão arterial.

O desenvolvimento do estudo ocorreu em conformidade com os preceitos éticos e foi respeitada a Resolução 196/96 do Conselho Nacional de Saúde do Ministério da Saúde, tendo sido o projeto aprovado pelo Comitê Permanente de Ética em Pesquisa com Seres Humanos (COPEP) da Universidade Estadual de Maringá (Parecer $n^{\circ}$ 085/2006). Todos os participantes foram orientados sobre a pesquisa e assinaram o Termo de Consentimento Livre e Esclarecido em duas vias, e para manter o sigilo dos municípios, eles foram identificados por M1, M2, M3, M4 e M5.

\section{RESULTADOS E DISCUSSÃO}

\section{Conhecendo os informantes}

Ao todo, participaram dos cinco grupos focais 44 profissionais de seis categorias diferentes, com maior representatividade dos agentes comunitários de saúde. Em sua maioria, os entrevistados eram do sexo feminino, situavam-se na faixa etária de 31 a 40 anos e tinham até cinco anos de atuação na ESF, o que é um período relativamente pequeno de experiência profissional nesta área de trabalho (tabela 1).

O município que apresentou maior número de profissionais participantes no grupo focal foi o M2. Isto se deveu ao fato de, estrategicamente, a coordenação da Unidade Básica de Saúde (UBS) ter agendado o grupo focal para o dia e período em que é realizada a reunião semanal da equipe, de forma que dele pudessem participar todos os profissionais atuantes na unidade. Já no M5 não houve a participação do enfermeiro, que estava presente na UBS, mas não mostrou interesse na discussão.

\section{$\mathrm{O}$ atendimento à pessoa com $\mathrm{HA}$ - características e dificuldades}

Os profissionais de todos os grupos iniciaram falando do atendimento às pessoas com hipertensão arterial no serviço, e nessa ocasião relataram algumas atividades desenvolvidas que são limitadas ao Sistema de Cadastro e Acompanhamento de Portadores de Hipertensão Arterial e Diabetes Mellitus (SIS-Hiperdia).
Tabela 1 - Caracterização dos participantes dos grupos focais quanto ao sexo, faixa etária, categoria profissional e tempo de atuação. Maringá-PR, 2008.

\begin{tabular}{lcccccc}
\hline Variáveis & M1 & M2 & M3 & M4 & M5 & Total \\
\hline Sexo & & & & & & \\
$\quad$ Feminino & 5 & 16 & 4 & 8 & 6 & $\mathbf{3 9}$ \\
$\quad 1$ & - & 2 & 2 & - & $\mathbf{5}$ \\
$\quad$ Masculino & & & & & & \\
$\quad$ Faixa etária & 1 & 3 & 4 & 4 & 2 & $\mathbf{1 4}$ \\
$\quad 19-30$ & 2 & 9 & 1 & 5 & 1 & $\mathbf{1 8}$ \\
$31-40$ & 3 & 4 & 1 & 1 & 3 & $\mathbf{1 2}$ \\
$\quad+41$ & & & & & & \\
Categoria profissional & 1 & 2 & 1 & 1 & - & $\mathbf{5}$ \\
$\quad$ Enfermeiro & - & 2 & - & - & 1 & $\mathbf{3}$ \\
$\quad$ Médico & - & - & - & - & 1 & $\mathbf{1}$ \\
$\quad$ Dentista & - & 1 & 2 & 1 & 2 & $\mathbf{6}$ \\
$\quad$ Auxiliar de enfermagem & - & 1 & - & - & - & $\mathbf{1}$ \\
$\quad$ Técnico de Enfermagem & 5 & 10 & 3 & 8 & 2 & $\mathbf{2 8}$ \\
$\quad$ Agente comunitário de saúde & 5 & & & & & \\
Tempo de atuação na ESF (anos) & & & & 7 & 4 & $\mathbf{3 6}$ \\
$\quad$ Até 5 & 3 & 16 & 6 & 3 & 2 & $\mathbf{8}$ \\
$\quad 6-10$ & 3 & - & - & $\mathbf{6}$ & $\mathbf{6}$ \\
\hline Total * & $\mathbf{6}$ & $\mathbf{1 6}$ & $\mathbf{6}$ & $\mathbf{1 0}$ & $\mathbf{6}$ & $\mathbf{4 4}$ \\
\hline
\end{tabular}

* Total de participantes de cada grupo focal

O grupo de hipertenso acontece uma vez por mês, onde verifica a pressão arterial, orienta e distribui a medicação... (M5).

Percebemos no relato que a organização do serviço desse município se preocupa com a demanda e a distribuição de receitas e medicações, reproduzindo o modelo da assistência curativa do atendimento às pessoas com HA e incorporando o SIS-Hiperdia como programa, esquecendo-se de que o Plano de Reorganização da Atenção à Hipertensão Arterial e ao Diabetes Mellitus vai muito além do cadastro de portadores de hipertensão e diabetes realizado por meio do SIS-Hiperdia, pois o propósito do Plano é a reorganização da Atenção Básica tendo como estratégias principais a prevenção dessas doenças, suas complicações e a promoção da saúde, objetivando, assim, uma melhor qualidade de vida. Diante do exposto, os grupos de hipertensão nas unidades de saúde devem constituir-se em espaços de orientação, discussão das dificuldades e formulação de estratégias para atender às necessidades da população ${ }^{(9)}$.

Os profissionais referiram que, independentemente de as pessoas com HA serem atendidos ou não pela UBS, todos os que residem na área de abrangência da qual fazem parte estão cadastrados no SIS-Hiperdia, porém aqueles que são acompanhados pela equipe de ESF são atendidos rotineiramente de acordo com os protocolos dos serviços de saúde, como pode ser observado nas falas a seguir.

Eles fazem consultas mensais, fazem os exames de rotina. tem também as visitas domiciliares mensais, onde a gente vê quem está tomando o remédio direito. Se não estão 
tomando, os ACSs orientam, e os outros profissionais (enfermeiro/médico) focam as visitas para os pacientes mais necessitados e com pressão alta (M4).

A gente faz as visitas e anota nas fichas para fazer o acompanhamento mensal, nós visitamos todos e registramos a data em uma planilha (M1).

Apreendemos dos comentários acima que a maioria dos profissionais de saúde deste estudo com formação superior priorizam os casos considerados mais "graves" na realização dos cuidados e visitas domiciliares, o que, de certa forma, está de acordo com o preconizado pelo Ministério de Saúde, que recomenda que o ACS realize visita domiciliar mensal e desenvolva ações que busquem a integração entre a equipe de saúde e a população adscrita, enquanto os demais profissionais da equipe devem realizar o cuidado em saúde da população e assistência integral aos indivíduos e famílias na USF e, quando indicado ou necessário, no domicílio e/ou nos demais espaços comunitários ${ }^{(10)}$.

É importante salientar que, para realizar atividades educativas regulares e desenvolver ações de prevenção e de promoção à saúde dos indivíduos, famílias e comunidade, a equipe deve estar preparada e conhecer a realidade da população atendida $^{(5)}$.

A visita domiciliar mensal proporciona maior proximidade com o usuário e sua família, demonstrando um grau de comprometimento maior ${ }^{(2)}$, como também a possibilidade de conhecer o indivíduo e a família e prestar assistência mais individualizada, com vistas a atender às suas reais necessidades; mas é compreensível que seja realizada com mais frequência pelos ACSs, os quais têm esta atribuição de visitar mensalmente as famílias e constituem um número de profissionais maior que o das outras categorias.

Os profissionais reconhecem que seria necessária uma melhoria na atenção, porém justificam a não realização das atividades preconizadas (por exemplo, mais visitas domiciliares, atenção e orientações quanto a dietas, exercícios físicos e outras) especialmente pelo excesso da demanda.

Tem gente que precisa de mais de uma visita no mês, mas se a gente fizer acaba não dando conta, porque tem outros programas, da criança e da gestante, por exemplo... (M4).

A gente ainda tem muita dificuldade para atender a todos de uma maneira correta (M1).

Nos depoimentos acima os entrevistados reconhecem que alguns indivíduos, em função da gravidade da doença e/ou das condições da família, precisariam de mais do que uma visita mensal, mas isto é inexequível, devido à demanda decorrente de outros programas e atividades que eles desenvolvem.

Estudo que avaliou a atenção à pessoa com HA também apontou como inadequada a área física das unidades de Saúde da Família para a assistência a estas pessoas de acordo com os princípios e diretrizes da ESF e do Plano de Reorganização da Atenção à Hipertensão Arterial e ao Diabetes Mellitus(11).
A HA é uma doença que, quando instalada, gera várias necessidades de atendimento especializado, sobretudo do cardiologista, mas também de outros especialistas, dependendo das doenças associadas. A despeito do atendimento especializado oferecido aos pacientes atendidos, os sujeitos da pesquisa relataram que existe uma rotina.

A gente passa os pacientes por consulta geral, encaminha se necessário, para especialidade; em uma semana no mês a gente recolhe os encaminhamentos que fica com as pessoas e manda para a central de agendamentos da UBS (M3).

Ao comentarem as rotinas do serviço, normalmente iniciava-se a discussão das dificuldades encontradas pelos profissionais no desempenho das atividades, entre as quais se destacaram a falta de material de consumo e equipamentos e a inadequação da estrutura física para o atendimento.

A gente faz a reunião do grupo de hipertenso na varanda do posto, por falta de espaço. O nosso maior problema aqui é espaço físico (M5).

Faz 20 dias que nós não temos prontuário, por que falta folha de sulfite. Não temos um monte de coisas, falta até aparelho de pressão (M2).

Estudo que avaliou a atenção ao hipertenso também apontou como inadequada a área física das unidades de Saúde da Família para a atenção do hipertenso de acordo com os princípios e diretrizes da ESF e do Hiperdia ${ }^{(11)}$.

Destaca-se que para a prestação de um cuidado integral é preciso dispor de um ambiente que permita acolher o paciente e de equipamentos que possibilitem aos profissionais desenvolver suas tarefas. É necessário também que os serviços contem com profissionais habilitados para ouvir e compreender o paciente nas suas reais necessidades, oferecendo-lhes orientações de forma individualizada e de acordo com as diretrizes preconizadas pelo Humaniza SUS. Não obstante, os depoentes relataram que as maiores dificuldades estão relacionadas ao comportamento dos pacientes e/ou familiares, como, por exemplo, a não adesão ao tratamento.

O paciente não adere mesmo, devido a suas crenças e valores. Como ele vive o que ele acha importante, aquela coisa de que nunca vai acontecer com ele... Então a ACS tem que ir até a sua casa, e fazer uma busca ativa (M2).

Tem alguns pacientes rebeldes, eles não tomam o medicamento na hora certa, a quantidade certa; tomam no dia que quer e não cuidam da alimentação (M4).

A adesão ao tratamento é definida como o grau de comprometimento com as medidas terapêuticas indicadas, sejam elas medicamentosas ou não, com o objetivo de manter a pressão arterial em níveis normais ${ }^{(12)}$. Os fatores que podem influenciar a adesão ao tratamento estão relacionados ao sexo, idade, 
etnia, condições socioeconômicas, hábitos de vida, aspectos culturais, gestão do modelo assistencial e habilidades e integração da equipe de saúde ${ }^{(13)}$.

A adesão terapêutica é a extensão em que a pessoa segue as recomendações do profissional de saúde relacionadas à adoção do uso de medicamentos e mudanças no estilo de vida $^{(14)}$. Destarte, é relevante entender o comportamento dos pacientes que não aderem ao tratamento, para que os profissionais de saúde envolvidos no atendimento, principalmente o enfermeiro, compreendam sua realidade para poderem agir comunicativamente com eles, dando-lhes orientações para motivar a adesão ao tratamento e, ao mesmo tempo, perceberem-se como agentes de mudança, a partir da implementação de programas educativos e avaliativos voltados à melhoria das ações desenvolvidas, buscando a adaptação destas atividades à realidade dos indivíduos e assim contribuindo para melhorar e manter sua saúde ${ }^{(15)}$.

Nos cincos municípios estudados os profissionais fizeram referência à dificuldade de os pacientes aderirem ao tratamento, seja na ingestão dos medicamentos, seja na realização de exercícios físicos, seja ainda no seguimento de um regime alimentar.

O dia em que ele vai beber pinga ele não toma o remédio, e ele não assume isto, mas ele fala para a mulher que se ele está com a pressão alta ele vai e toma um gole de pinga e baixa a pressão (M2).

A gente convida para caminhada, mas não se importam muito. Tem umas três ou quatro pessoas que toda terça e quinta estão aqui, e uns e outros que aparecem de vez em quando (M3).

O paciente acreditar que o tratamento traz benefício para sua saúde é importante para sua adesão à terapia ${ }^{(16)}$. Para isso em alguns momentos é necessário que o profissional se disponha a explicar a importância do tratamento, mesmo o paciente sendo resistente e descrente. Foi observado também que, apesar de muitos indivíduos, especialmente os idosos, apresentarem dificuldades em compreender algumas orientações, estes participam de forma efetiva das atividades grupais.

Os idosos têm mais dificuldade de entender o que a gente fala... mas eles vêm mais nas atividades...(M3).

É possível inferir, a partir da mensagem, que a presença dos idosos nos grupos pode dever-se a duas razões: sua disponibilidade de tempo, por serem aposentados, e/ou a busca de companhia, já que, como eles geralmente se encontram solitários em seus domicílios durante o dia, a participação no grupo é ao mesmo tempo uma ocupação e um encontro de colegas/amigos.

É imprescindível considerar que o tratamento da HA exige muitas mudanças no estilo de vida do indivíduo, entre elas o controle do peso, a adoção de dieta hipossódica e balanceada, aumento da ingesta de frutas e verduras, redução no uso de bebidas alcoólicas, realização de exercícios físicos, suspensão ou atenuação do tabagismo e substituição da gordura saturada por polinsaturada e monoinsaturada. O problema é que, muitas vezes, o portador de doença crônica enfrenta, além de outras, também dificuldades socioeconômicas, o que se torna um empecilho para uma adequada adesão ${ }^{(17)}$. A não adesão ao tratamento se deve também a não aceitação da doença.

Os mais jovens não querem tomar medicamento, não querem vir na reunião, não querem passar por consulta médica, muitas vezes não aceitam a sua doença... (M3).

Ao fazerem referência aos indivíduos de 45 a 60 anos os profissionais consideram que os fatos de estar em uma faixa etária jovem e de a doença ser assintomática levam o indivíduo a demonstrar desinteresse em aderir ao tratamento, e que isto pode levar a complicações e até mesmo à morte.

Muitos não aceitam a doença, insistem em afirmar que a pressão está boa... Ele não se acha doente, na verdade ele é jovem, ele acredita que não precisa vir na unidade, não precisa vir na reunião (M2).

Tem uma paciente que trabalhou no hospital por 20 anos como atendente de enfermagem e sabe o que é hipertensão arterial. Ela pesa aproximadamente $250 \mathrm{~kg}$, eu fui verificar a pressão dela, e ela disse: "Ah,! eu estou contente a minha pressão está 25X15" (M2).

Neste caso verificamos que, quando o paciente está acostumado com a sintomatologia, passa a não considerá-la um sinal importante de gravidade da doença. Estes indivíduos precisam de uma abordagem diferenciada, que permita desvelar todas as complicações possíveis no curso da doença e desencadeie a sensibilização necessária para estimular a adoção de hábitos mais saudáveis.

No tocante à adesão ao tratamento para a manutenção da pressão arterial em níveis normais, faz-se necessário considerar que a participação da família é muito importante, pois o domicílio é visto hoje como um espaço em que as pessoas com doenças crônicas podem manter a estabilidade de sua condição, o que faz da vivência de cuidar de um doente em casa uma experiência cada vez mais crescente. Por isso a família deve estar profundamente envolvida no tratamento e oferecer cuidados que favoreçam a adesão do indivíduo com $\mathrm{HA}$ ao tratamento ${ }^{(18)}$.

Tem pacientes que moram sozinhos, não têm apoio da família. E tem aqueles que têm família, mas às vezes não têm a devida atenção (M4).

Sem o apoio da família, a gente não consegue fazer nada por aquele paciente (M4).

A compreensão do processo de envolvimento da família no cuidado prestado ao indivíduo com $\mathrm{HA}$ contribui de forma significativa para a prática profissional, favorecendo a reflexão e, consequentemente, possíveis mudanças nas atitudes 
profissionais relacionadas à assistência ao indivíduo e sua família. Além disso, fornece subsídios para planejar novas formas de ver e cuidar, com base nas concepções, nos meios de assistir e nas necessidades apresentadas por essa família(19).

Em um estudo realizado com famílias de idosos com $\mathrm{HA}$, foi evidenciada a necessidade de o profissional de saúde conhecer com propriedade a realidade de vida da população circunscrita à área de abrangência de sua UBS, pois o estabelecimento de vínculo entre a equipe e a família oferece perspectivas para minimizar o desconhecimento da família sobre os problemas que acometem sua saúde, como também permite ao profissional compreender as particularidades da complexa rede de cuidado e suporte que envolve cada uma $\operatorname{delas}^{(20)}$.

Este é um fato grave quando se pensa nos óbitos por HA de pessoas na faixa etária de 45 a 65 anos. Acreditando-se que são óbitos evitáveis, durante a realização do grupo focal perguntou-se aos participantes, se eles tinham conhecimento de óbitos de usuários com hipertensão em sua área de abrangência. O que se constatou foi que, apesar de já ter-se passado mais de um ano, de modo geral, pelo menos um ou dois profissionais de cada município, em especial os agentes comunitários, conseguiram se lembrar dos casos apresentados, tendo-se constatado, por exemplo, que dois indivíduos não eram moradores da área de abrangência e que, quando morreram, estavam na casa de parentes. Nos outros três casos, os indivíduos eram acompanhados pela equipe de Saúde da Família e os profissionais se lembraram do indivíduo pelo nome e discutiram com facilidade características relacionadas com o acompanhamento e a conduta deles e até de suas famílias. Segundo esses profissionais, apenas uma fazia uso das medicações, enquanto os outros dois não seguiam as orientações nem faziam uso das medicações prescritas.

Ao identificarem os indivíduos que foram a óbito e deles se recordarem, os profissionais, de certa forma, demonstraram conhecimento e comprometimento com a população de sua área de abrangência.

A paciente veio de Rondônia para morar com a família e fazer tratamento e acabou morrendo (M1).

A gente ia visitar todo mês e não encontrava, tinha que bater na mesma tecla... Tinha dificuldade de encontrá-la... mas ela aderiu ao tratamento medicamentoso, dizia que fazia exercício físico todos os dias, andava muito para ir ao trabalho e pegava peso, por ser empregada doméstica (M2).

Ainda em relação às dificuldades apontadas para trabalhar com a pessoa com HA na faixa etária entre 45 a 65 anos, observamos que elas variaram desde a não adesão ao tratamento até a falta de infraestrutura física e de recursos humanos das equipes de saúde; mas em muitas ocasiões as dificuldades e obstáculos para incorporar os ensinamentos e a falta de tempo para participar das atividades propostas pelas UBS foram identificadas como os fatores que mais afetavam a continuidade do trabalho dos profissionais.
O nosso horário de trabalho é comercial, muitas vezes não encontramos os pacientes em casa, pois os pacientes jovens estão em atividade profissional (M2).

As pessoas que trabalham jamais vão perder um dia de trabalho para ir ao médico, ou à reunião se não estão sentindo nada, mesmo sabendo que têm pressão alta, porque eles deixam de ganhar (M2).

Tanto o indivíduo com HA como o seu familiar, na maioria das vezes, têm vínculo empregatício e acham que não podem ausentar-se do trabalho para participar das atividades oferecidas na UBS. Vale ressaltar que a Atenção Básica à Saúde não privilegia a atenção à saúde do adulto, uma vez suas atividades estão mais voltadas à saúde da criança, da mulher e do idoso. Não obstante, com base nos resultados encontrados nos outros subprojetos da pesquisa matricial, os quais mostraram que indivíduos jovens (na faixa etária de 45 a 64 anos) estão morrendo em decorrência da $\mathrm{HA}^{(21)}$, verifica-se a necessidade de o serviço criar estratégias para acompanhar e controlar a saúde de indivíduos adultos, no sentido de prevenir e tratar doenças para melhorar sua qualidade de vida e evitar complicações que impliquem no afastamento de suas funções produtivas e resultem em ônus para ele e para a sociedade. Estas estratégias podem envolver parcerias com empresas, por exemplo, com o intuito de que estas abram suas portas para o setor saúde ao menos uma vez ao ano. Nestes casos, os profissionais poderiam se deslocar até a empresa ou esta poderia liberar seus funcionários ao menos uma vez por ano para a realização de ações preventivas. Para isto seria necessário que o serviço também se preparasse para uma atuação de caráter de promoção e prevenção, abrindo agenda específica voltada a esta questão; porém isto só será possível quando o próprio setor saúde conseguir reconhecer a importância e o impacto de ações preventivas em adultos, que em sua maioria se encontram no mercado de trabalho e não têm horário compatível com o funcionamento das UBS, o que os leva a procurar o serviço de saúde só em situações de doença.

Ainda nesta linha de pensamento, as UBSs podem tentar sensibilizar as empresas quanto à importância da ginástica laboral, e em pareceria com a secretaria de esportes do município ou mesmo com instituições de ensino, promover atividades físicas e recreativas como, por exemplo, futebol, caminhadas, atletismo, vôlei, corridas de bicicleta, etc. Estas atividades devem ser oferecidas para todas as faixas etárias e em dias e horários alternativos, de modo que delas possam participar todas as pessoas, e não apenas idosos e crianças.

Estratégias de intervenção para adesão ao tratamento da HA

As discussões apontaram algumas estratégias de atuação que poderiam ser implementadas ou que os profissionais gostariam de implementar diante das dificuldades encontradas no cotidiano de cuidado à pessoa com HA, algumas delas inclusive já em uso pela equipe. Dentre elas, a mais citada diz respeito às tentativas de facilitar o uso correto da medicação:

Eu faço aquelas carteirinhas recortadas com o número certo dos medicamentos e anoto o dia que vai acabar. Se 
sobrar ou faltar é porque o paciente está tomando o medicamento errado, e nós precisamos identificar o porquê. Quando isso acontece, vamos até a pessoa e conversamos para saber o que está acontecendo, se está tomando errado, se está emprestando ou dando para alguém. Se sobra, por que não está tomando... Fazemos isto principalmente para aquelas pessoas que nas consultas para pegar medicação ou nas visitas domiciliares percebíamos que existiam muitos ou poucos remédios. Depois que começamos a controlar mais, este problema diminuiu (M3).

A estratégia de utilizar carteirinhas controladas demonstra o uso correto ou incorreto da medicação, porém não permite saber se os medicamentos estão sendo tomados nos horários corretos nem possibilita o controle de outras formas de adesão ao tratamento, como o uso de uma alimentação saudável e a prática de atividade física.

Confeccionamos sacolas de tecido jeans que ganhamos retalho, e ilustramos com o desenho adequado, sol para tomar o medicamento pela manhã, prato significando almoço e lua à noite. Quando entregamos, já orientamos a forma de tomar o medicamento, e entregamos o número de sacolinha adequada para cada horário. Interessante que para alguns pacientes quanto mais sacolinhas ele ganhava mais feliz ele ficava. Parece que não entendia que isto significava a quantidade de medicamentos que ele tomava, ou seja, que ele podia estar mais grave que outros pacientes (risos). Esta estratégia ajudou muito na diminuição de erros de tomada de medicação, principalmente de esquecimento, até porque, mesmo que ele tome três comprimidos à noite, nós colocamos todos dentro da mesma sacola a quantidade que tem a tomar no mês. A sacolinha vai com o nome e o número do prontuário de cada um, e assim, fica difícil errar, além dela ser bem bonitinha (M5).

Neste município a dentista mostrou-se muito preocupada com o tratamento odontológico da pessoa com HA, por esta razão diz ficar atenta em conjunto com a equipe, buscando a estabilidade do quadro de saúde desta pessoa para evitar complicações odontológicas. Neste sentido, referiu observar e reforçar as orientações relativas ao uso da medicação, pois reconhece a importância da adesão ao tratamento. Em relação ao uso de sacolas de tecido jeans adotadas fez o seguinte comentário:

Até o momento, em termos de resultados observados, esta foi a melhor estratégia já adotada para facilitar a adesão aos medicamentos pelos pacientes (M5).

Os profissionais dos cinco municípios relataram utilizar alguma estratégia com o intuito de incentivar a adesão ao tratamento prescrito; no entanto, ao falarem das estratégias, cada equipe relata que até chegar a mais adequada foram feitas várias tentativas, com acertos e erros.

É importante reforçar que as estratégias devem ser pensadas a partir da realidade e das dificuldades que se encontram no âmbito de atuação, de forma a facilitar o serviço e garantir ao usuário uma assistência adequada. Observa-se na fala abaixo que as estratégias são pensadas também para atender pacientes com necessidades especiais.

Quando o paciente é cego, a enfermeira coloca uma fita adesiva na caixa se tem que tomar um comprimido e duas fitas quando precisa tomar dois comprimidos (M2).

Atuar em promoção à saúde não consiste simplesmente em orientar no sentido de mudanças de comportamento, mas também em trabalhar com as potencialidades de cada comunidade e com os valores que possibilitem transformação, conscientização e, por conseguinte, um novo entendimento de cidadania $^{(22)}$.

Toda informação/orientação deve ser fornecida de forma individualizada, respeitando-se as necessidades e atendendo-se às expectativas de cada indivíduo. A orientação constitui hoje uma importante ferramenta para a atuação do profissional de saúde, pois, quando bem realizada, permite-lhe estabelecer, juntamente com o usuário, a responsabilidade partilhada na realização dos cuidados. A importância da orientação adequada é reconhecida pelos profissionais.

Nós fazemos um trabalho bem legal no sentido de orientar. Falamos para fazer caminhada, vir nas reuniões, não comer carne gordurosa, muito sal, entre outras... (M2).

Tem grupo de ginástica que ocorre de segunda e quarta-feira... e orientamos para que todos venham (M5).

O importante é sempre estar conversando com o paciente e a família para saber o que eles acham do atendimento... (M1).

O paciente que recebe explicações claras e compreende a razão e a importância do tratamento também tem mais vontade de cooperar. É mais provável que as pessoas cooperem se acreditarem que os profissionais da saúde envolvidos se preocupam realmente com sua saúde.

A interação dos profissionais de saúde com os cuidadores é um aspecto importante para que os pacientes cooperem com o plano terapêutico. Então, ao participarem do planejamento de seu tratamento, as pessoas assumem a responsabilidade por ele, aumentando a probabilidade de mantê-lo ${ }^{(14)}$.

\section{CONSIDERAÇÕES FINAIS}

Ao finalizar este estudo, percebemos que a assistência, em todas as UBSs pesquisadas, de uma maneira geral, atende às necessidades mais urgentes da população que busca o serviço de saúde; porém, mesmo adotando estratégias para a adesão ao tratamento, os profissionais não conseguem atingir toda a população, por várias causas, entre elas o horário de atendimento, a não compreensão/aceitação da doença, questões relacionadas à família, entre outras, o que pode implicar na qualidade da assistência, apesar do esforço e comprometimento da equipe. 
É essencial que o profissional de saúde compreenda a realidade onde atua e reflita sobre a sua prática, para que possa atender de forma humana e integral o indivíduo com HA ou com outras necessidades.

Neste contexto, a compreensão referente ao cuidado prestado pela equipe ao indivíduo com hipertensão contribui de forma significativa para a prática profissional, favorecendo a reflexão e, consequentemente, possíveis mudanças nas atitudes profissionais em relação à assistência ao indivíduo e sua família. Além disso, fornece subsídios para fundamentar novas formas de ver e atender a família, baseando-se nas concepções, nos meios de cuidar e nas necessidades que ela apresenta, com vistas a tornar o cuidado individualizado e pautado na realidade.

Ao se buscar reconstruir o serviço oferecido às pessoas com HA sob a ótica dos profissionais de saúde, observou-se que, apesar de o estudo ter sido realizado com equipes de diferentes municípios e, por consequência, com realidades distintas, os significados e percepções em relação ao atendimento prestado e às dificuldades experienciadas são semelhantes em muitos aspectos. Por outro lado, é importante considerar que as formas de trabalhar estas dificuldades são diferentes e que a proposta metodológica adotada no estudo permitiu aos profissionais pensar e discutir sobre a atenção oferecida aos indivíduos com HA, como também compreender melhor suas rotinas e as necessidades do serviço.

Em relação às limitações do estudo, é importante lembrar que estes dados integram os obtidos em um estudo maior financiado pelo CNPq, e como se trata de um subprojeto, tivemos algumas limitações para desenvolvê-lo, entre as quais podemos destacar o fato de o estudo matricial ter envolvido a Macrorregião Noroeste de Saúde do Estado do Paraná, que engloba cinco regionais de saúde e um total de 115 municípios, alguns distantes mais de $300 \mathrm{~km}$ de Maringá. Isto fez com que as pesquisadoras optassem por realizar a coleta de dados correspondente a este subprojeto apenas nos municípios sedes de regional de saúde e por realizar apenas um grupo focal em cada município. Destarte, os resultados encontrados certamente não representam a realidade dos municípios das regionais. Outro aspecto a considerar é a dificuldade de reunir os profissionais da equipe para a realização dos grupos focais, em virtude da demanda de atividades e até mesmo do desinteresse de alguns em participar do estudo. Neste sentido nos chamou particularmente a atenção o fato de um dos enfermeiros, apesar de presente na unidade, não querer participar do estudo. A causa disto é que este profissional normalmente é o que mais se mostra sensibilizado e interessado em discutir formas de melhorar a assistência que é prestada na UBS. Também podemos considerar como limitação do estudo a inexistência de local apropriado para o desenvolvimento do grupo focal em algumas UBSs, o que comprometeu a disposição dos participantes em círculo e até mesmo a gravação das falas.

Consideramos de grande importância estudos que avaliam a assistência a partir da percepção dos profissionais. Neste estudo foi possível perceber que, quando se pensa e discute em grupo sobre a prática cotidiana e suas dificuldades, podem surgir novas ideias e serem propostas novas maneiras de conduzir a atuação dos profissionais, as quais podem ser compartilhadas para melhorar o atendimento em saúde da população.

\section{REFERÊNCIAS}

1. Silva MEDC, Barbosa LDCS, Oliveira ADS, Gouveia MTO, Nunes BMVT, Alves ELM. As representações sociais de mulheres portadoras de Hipertensão Arterial. Rev Bras Enferm 2008;61(4):500-7.

2. Mantovani MF, Mottin JV, Rodrigues J. Visita domiciliar de enfermagem com atividades educativas no tratamento da pressão arterial. Online Braz J Nurs [periódico na Internet]. 2007 April [acesso em 3 set 2009];21;6(1) Disponível em: <http://www. uff.br/objnursing/index.php/nursing/article/view/757> .

3. Ministério da Saúde. Datasus [homepage na internet] Informações de Saúde. Estatísticas vitais - Mortalidade e nascidos vivos [acesso em 27 ago 2011]. Disponível em: < http://tabnet. datasus.gov.br $>$.

4. Paiva DCP, Bersusa AAS, Escuder MML. Avaliação da assistência ao paciente com diabetes e/ou hipertensão pelo Programa Saúde da Família do Município de Francisco Morato, São Paulo, Brasil. Cad Saúde Pública 2006; 22(2):377-85.

5. Toledo MM; Rodrigues SC, Chiesa AM. Educação em saúde no enfrentamento da hipertensão arterial: uma nova ótica para um velho problema. Texto \& Contexto Enferm 2007;16(2):233-8.

6. Leopardi MT, Beck CLC., Nietsche EA, Gonzales RMB. Metodologia da Pesquisa na Saúde. 2. ed. Florianópolis:UFSC/
Pós-Graduação em Enfermagem; 2002.

7. Minayo MCS. O desafio do conhecimento: pesquisa qualitativa em saúde. São Paulo: Hucitec; 2007.

8. Bardim, L. Análise de Conteúdo. Lisboa: Edições 70; 2008.

9. Ministério da Saúde. Secretaria de Políticas Públicas. Plano de reorganização da atenção à hipertensão arterial e ao Diabetes Mellitus. Brasília: Ministério da Saúde; 2001.

10. Ministério da Saúde (Brasil). Portaria $n^{\circ} .648$, de 28 de março de 2006. Diretrizes e Normas para a Atenção Básica. Diário Oficial da União 28 março de 2006.

11. Costa JMBS, Silva MRF, Carvalho EF. Avaliação da implantação da atenção à hipertensão arterial pelas equipes de Saúde da Família do município do Recife (PE, Brasil). Ciênc Saúde Coletiva 2011; 16(2):623-33.

12. Torres JCT, Melo MN, Barba OAV, Venâncio TE, Resende TU, Fontes VB, et al. Hipertensão arterial: uma visão holística. Rev Bras Hipertens 2006;13(4):328-30.

13. Didier MT, Guimarães AC. Otimização de recursos no cuidado primário da hipertensão arterial. Arq Bras Cardiol 2007;88(2):218-24. 
14. Sabaté E, editor, World Health Organization. Adherence to long-term therapies: evidence for action. Geneva: World Health Organization; 2003.

15. Linck CL, Bielemann VLM, Sousa AS, Lange C. Paciente crônico frente ao adoecer e a aderência ao tratamento. Acta Paul Enferm 2008;21(2):317-22.

16. Matos YLR, Alfonso LM, Vea HB. Adherencia terapêutica y factores psicosociales em pacientes hipertensos. Rev Cubana Med Gen Integr [periódico na Internet]. 2007 Mar [acesso 31 ago 2009];23(1) Disponível em: <http://scielo.sld.cu/scielo.php?script=sci arttext\&pid $=$ S0864-21252007000100005\&lng $=e s \& n r m=\bar{i}$ so $>$.

17. Rolim MO, Castro M. Adesão às orientações fornecidas no programa de controle da hipertensão: uma aproximação aos resultados padronizados de enfermagem. Online Braz J Nurs [periódico na internet]. 2007 abr [acesso em 3 set 2009]:21 6(1) Disponível em: <http://www.uff.br/objnursing/index. php/nursing/article/view/713>.

18. Saraiva KRO, Santos ZMSA, Landim FLP, Lima HP, Sena VL. O processo de viver do familiar cuidador na adesão do usuário hipertenso ao tratamento. Texto \& Contexto Enferm 2007; 16(1):63-70.

19. Lopes $\mathrm{MCL}$, Marcon SS. A Hipertensão arterial e a família: a necessidade do cuidado familiar. Rev Esc Enferm USP 2009; 43(2): 343-350.

20. Contiero AP, Pozati MPS, Challouts RI, Carreira L, Marcon SS. Idoso com hipertensão arterial: dificuldades de acompanhamento na Estratégia Saúde da Família. Rev Gaúch Enferm 2009;30(1):62-70.

21. Furukawa TS, Mathias TA, Freitas, Marcon SS. Mortalidade por doenças cerebrovasculares por residência e local de ocorrência do óbito. Cad Saúde Pública 2011;27:327-34.

22. Ferraz ST. A saúde fora do setor saúde ou lições da Agenda 21. Promoç Saúde 2000;2(3):12-4. 